\title{
Modern and physiological concepts of eyelid rejuvenation
}

\author{
André Camirand MD, Jocelyne Doucet RN, June Harris MD \\ Chirurgie Esthétique et Plastique, Montréal, Québec; and Faculty of Medicine, Memorial University of \\ Newfoundland, St John's, Newfoundland
}

\begin{abstract}
A Camirand, J Doucet, J Harris. Modern and physiological concepts of eyelid rejuvenation. Can J Plast Surg 1997; 5(2):105-111. Detailed consideration is given to rejuvenation of the upper and lower eyelids and periorbital area using modern and physiological concepts that are based on reversing the effects of ageing. A new idea is proposed for the pathophysiology of herniated fat pads of the lower eyelids. This concept must be kept in mind when considering the management and prevention of enophthalmia. Techniques to improve the infraorbital sulcus, crow's feet and eyebrow ptosis during aesthetic surgery are also presented.
\end{abstract}

Key Words: Canthopexy, Capsulopalpebral fascia, Enophthalmia, Herniated fat pads, Infraorbital sulcus, Superficial musculo-aponeurotic system

\section{Le rajeunissement de l'oeil, un concept physiologique et moderne}

RÉSUMÉ : Nous offrons avec détail une façon de rajeunir les paupières et la région péri-orbitaire. Ces méthodes physiologiques et modernes s'adresse directement au phénomène de vieillissement. Nous tentons d'expliquer la pathophysiologie des hernies graisseuses ainsi de l'enophthalmia du vieillissement et bien entendu comment y remédier sans les inconvénients des techniques conventionnelles. Nous discuterons également du sillon infra-orbitaire, de la ptôse du sourcil ainsi que les pattes d'oies.

$\mathrm{R}$ ejuvenation of the upper and lower eyelids is considered, with emphasis on reversing the effects of ageing.

\section{UPPER EYELIDS}

When considering rejuvenating the upper eyelids, it must be understood that with age, the eyebrow (Table 1) gravitates downward, causing a pseudodermachalasis of the upper eyelids. This, in turn, is responsible for static crow's feet, and with a receding hairline we get widening of the forehead. Because the eyebrow is low, it is raised to improve the appearance (in front of the mirror or when meeting someone) or field of vision. As a consequence, the frontalis, procerus and corrugator muscles hypertrophy and forehead wrinkles develop.

For us, it is not advisable to routinely excise skin and fat pads from the upper eyelids. This procedure reduces the distance between the eyebrows and the eyelashes and creates a 'sunken eye' (Figure 1) and a contrast between the skin inferior to the eyebrows and that of the upper eyelids, which are different in colour, texture and thickness). In addition, it may

Correspondence and reprints: Dr A Camirand, Chirurgie Esthétique et Plastique, 12245 rue Grenet, Suite 112, Montréal, Québec H4J 2J6. Telephone 514-745-1360, fax 514-745-5906, e-mail camirand@ total.net

\section{TABLE 1: The ageing eye}

1. Brow gravitates downward causing:

- Pseudodermachalasis of the upper eyelids

- Corrugator, procerus and frontalis wrinkles

- Static crow's feet

- Widened forehead (concomitant receding hairline)

- Reduced distance between the eyebrow and the eyelashes

2. Lateral canthus gravitates downward causing:

- Decreased mongoloid slant

- Pseudodermachalasis of the lower eyelids

- Herniated fat pads

- Scleral show

- Enophthalmia

3. Premalar fat pads gravitate downward (worsened by lower eyelid herniated fat pads) causing:

- Infraorbital sulci

prevent the a future brow lift because the patient would have lagophthalmia.

A brow lift, on the other hand, may give a proper location and arch to the eyebrows (Figure 2), restore the original dis- 

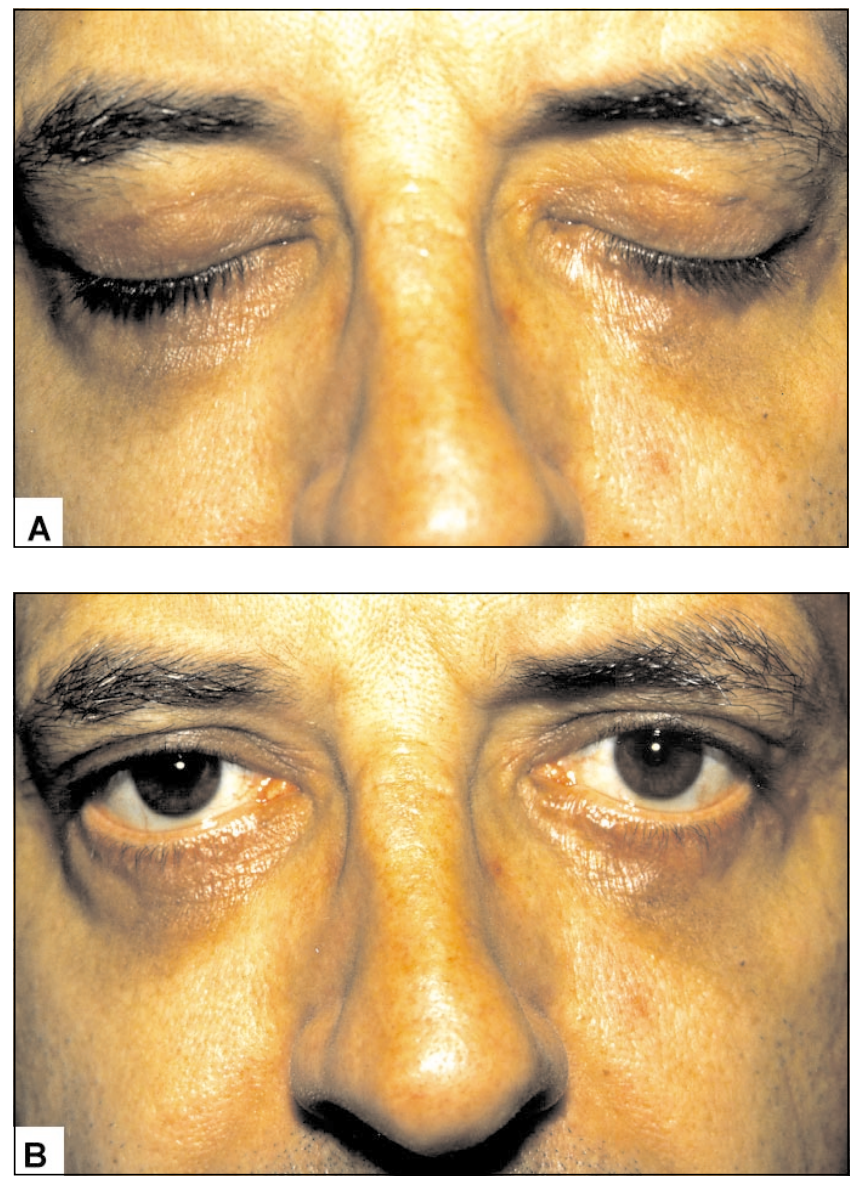

Figure 1) A patient after a conventional upper and lower blepharoplasty showing (A) an antimongoloid slant; a striking contrast between the pretarsal skin and the skin inferior to the eyebrow; and (B) scleral show; a decreased distance between the eyebrow and eyelashes; and enophthalmia
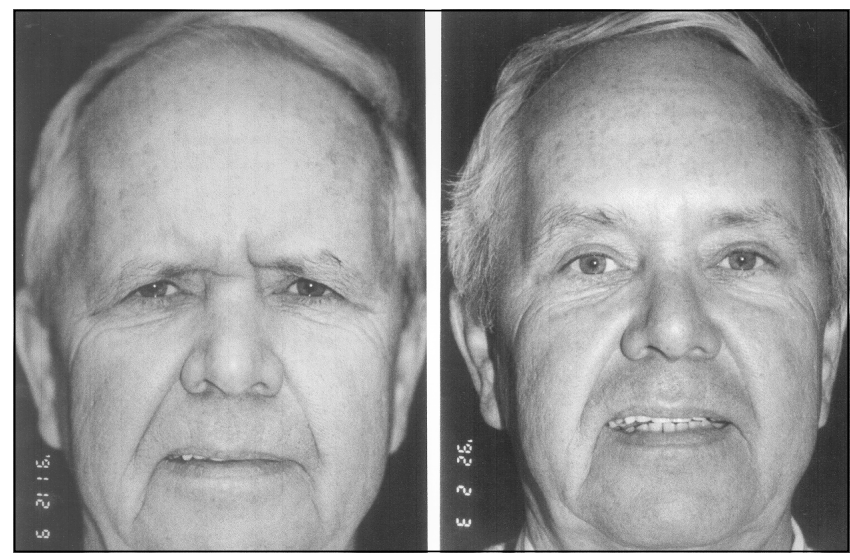

Figure 2) Preoperative (A) and postoperative views (B) of a patient managed by a brow lift and a lateral canthopexy

tance between the eyebrows and the eyelashes and eliminate pseudodermachalasis of the upper eyelids. Furthermore, by making a hairline incision perpendicular to the hair follicles $(1,2)$, scarring is minimized (Figure 4), the forehead is narrowed, and facial harmony is obtained (3-5). A coronal approach would further widen the forehead and break the
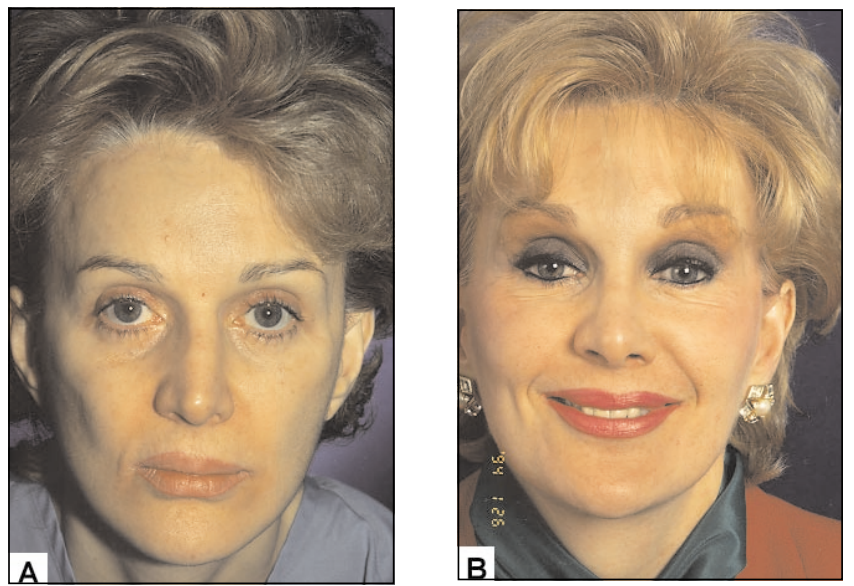

Figure 3) A patient following conventional upper and lower blepharoplasty (A) managed by brow lift and lateral canthopexy, thus eliminating the scleral show and producing an almond-shaped eye (B)

harmony of the face. If even 1.5 to $2.5 \mathrm{~cm}$ of forehead skin is removed, the procerus, corrugator, frontalis and orbicularis oculi muscles are weakened in some patients and the eyebrows may need to be raised further after only one year. Because skin is never removed by an endoscopic approach, the author never uses endoscopy for this procedure. After three months, when most swelling is gone, one can safely consider excising some skin from the upper eyelids. Skin resection is far smaller than in conventional upper blepharoplasty, reducing the contrast between the skin inferior to the eyebrow and the pretarsal skin. Skin resection will not lower the eyebrow.

As the brow is lifted, the herniated fat pads of the upper eyelids are exposed from above and coagulated to devascularize them, thus reducing volume and creating fibrosis (to prevent some of the herniation and eliminate the risk of hematoma). This must be done parsimoniously. If the volume of the herniated fat pad is reduced excessively, the eye may appear sunken and prematurely aged.

If a browlift is the only periorbital surgery, routine manipulation (incision, excision or coagulation) of the vertical fibres of the orbicularis oculi muscle should be done by the following approach. Continue the supraperiosteal dissection according to the preoperative markings of the upper and lower limits of the dynamic crow's feet to create a submuscular tunnel underneath the orbicularis oculi muscle; then, through the galea, create a subcutaneous (supramuscular) tunnel to easily manipulate (coagulate and incise) the vertical fibres of the orbicularis oculi. Not only does this technique manage the dynamic crow's feet, but it pulls up the tail of the eyebrow and prevents future downward pull, thus giving a much longer lasting result.

\section{LOWER EYELIDS}

A youthful-looking eye has a lateral canthus that is 2 to $3 \mathrm{~mm}$ above the medial canthus and we have a mongoloid orbital fissure or almond-shaped eye. The lower eyelid covers the lower limbus by 1 to $2 \mathrm{~mm}$, and the Lockwood suspensory 
TABLE 2: Herniated fat pad of the lower eyelid Pathophysiology

Lockwood suspensory ligament gravitates downward

$\downarrow$

Space between the globe and the floor reduces

$\downarrow$

Orbital fat projects anteriorly

$\downarrow$

Orbital septum stretches

$\downarrow$

Herniated fat pad

$\downarrow$

Enophthalmia develops

$\downarrow$

Infraorbital sulcus deepens

\section{TABLE 3: Causes of enophthalmia}

1. Genetic or age-related lowering of the globe

2. Herniated fat pads

3. Excessive excision of herniated fat pads

4. Coagulation of orbital fat

5. Resorption of orbital fat with age

ligament (mainly) (Figures 5,6) and the intraorbital fat (to a lesser degree) maintain the position of the eyeball in its normal upward, forward pointing position within the orbit.

With age the lateral canthus gravitates downward (Table 2) creating a pseudodermachalasis, reducing the mongoloid fissure and creating herniated fat pads and scleral show. Skin removal rarely improves this condition and increases the risk of worsening the scleral show. Herniated fat pads result from a decreased space between the eyeball and the floor of the orbit. This, in combination with a non stretchable, cone-shaped orbit, causes the orbital fat to be projected forward, stretching the orbital septum, the orbicularis oculi muscle and the skin. Plastic surgeons are taught that with age the inferior orbital septum becomes thin and weak and therefore stretches, causing herniated fat pads. The results of surgical interventions do not support this concept, and it seems more reasonable to believe that the septum is always thin and weak and therefore, cannot be the cause of hernias. In the author's experience, every time the orbital septum has been torn (for example, as a result of a fracture of the orbital floor) no herniated fat pad was seen, even if the septum was left open.

It is also worth noting that lacerations of the lower eyelids are often deep enough to involve the orbital septum. Skin closure does not include repair of the orbital septum, but patients do not subsequently demonstrate evidence of herniated fat pads. Therefore, the author proposes that herniated fat pads result, not from an over-abundance of orbital fat and subse-
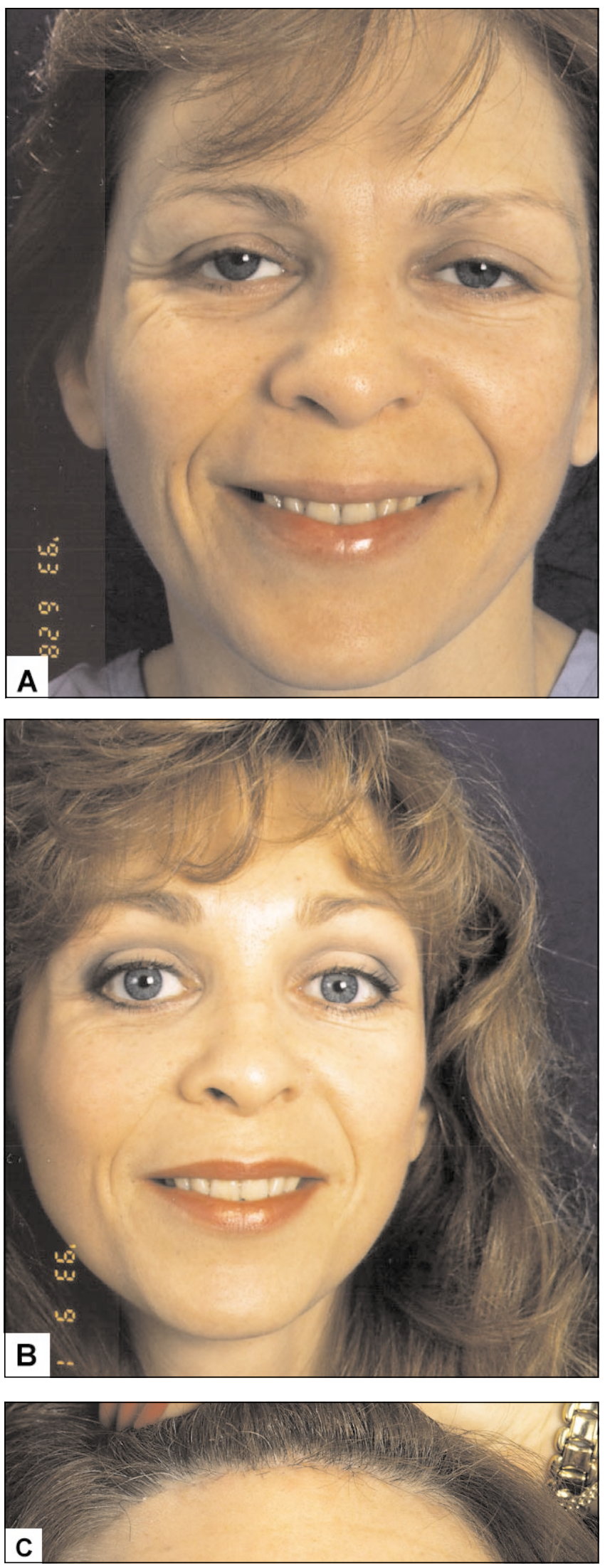

Figure 4) A patient with eyebrow ptosis and an antimongoloid fissure (A) who requested upper and lower blepharoplasty. Instead, she was managed by a brow lift and lateral canthopexy, thus eliminating the eyebrow ptosis and dynamic and static crow's feet and producing an almond-shaped eye $(\mathbf{B})$. The scar is virtually invisible $(\mathbf{C})$ 


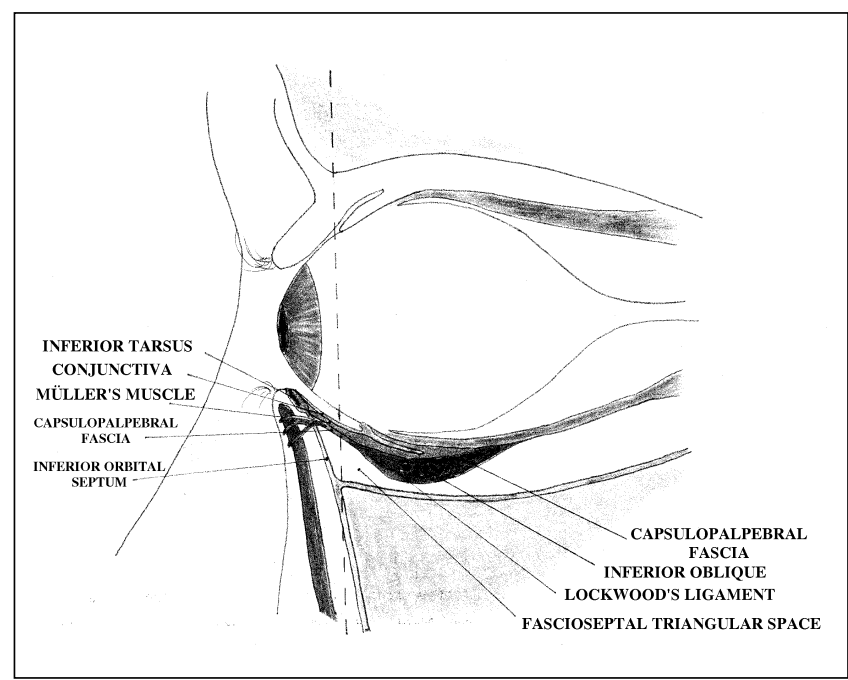

Figure 5) Schematic drawing of the anatomy of a youthful eyeball within the orbit

\section{TABLE 4: Management and prevention of enophthalmia}

1. Raise the eyeball with a proper canthopexy

2. Relocate herniated fat pads with the capsulopalpebral fascia

3. Use the superficial musculo-aponeurotic system to buttress the lower herniated fat pads during a face lift

quent stretching of the orbital septum, but from the lowering of Lockwood's suspensory ligament and forward displacement of this fat. (When patients have excess intraorbital fat, they exhibit exophthalmia). As the fat moves forward, there is an inevitable downward and backward displacement of the globe, creating enophthalmia (Table 3) or a 'sunken eye'. Moreover, the volume of orbital fat decreases with age. If the fat pads are excised aggressively, the enophthalmia is aggravated. Coagulation and resorption of the fat with age also aggravate enophthalmia.

The space between the globe and the floor of the orbit may diminish if the Lockwood's suspensory ligament lengthens genetically or descends with the lateral canthus, which gravitates downward with age. Lockwood's suspensory ligament determines globe level and is attached to the lateral retinaculum (Figures 5,6).

If a proper canthopexy $(6,7)$ is performed, the Lockwood's suspensory ligament is raised. This increases the space between the globe and the orbit floor and reduces the herniated fat pads, thus improving the enophthalmia (Table 4). In addition, it recreates the mongoloid fissure of youth, covers the lower limbus and redrapes the wrinkled skin, which can be improved further by concomitant chemical peeling or laser resurfacing. This procedure eliminates the risks of scleral show, retrobulbar hematoma and possible blindness, thus simplifying informed consent for the patient.

Another method of treating herniated fat pads is a transconjunctival approach $(7,8)$ opposite the arcus marginalis of

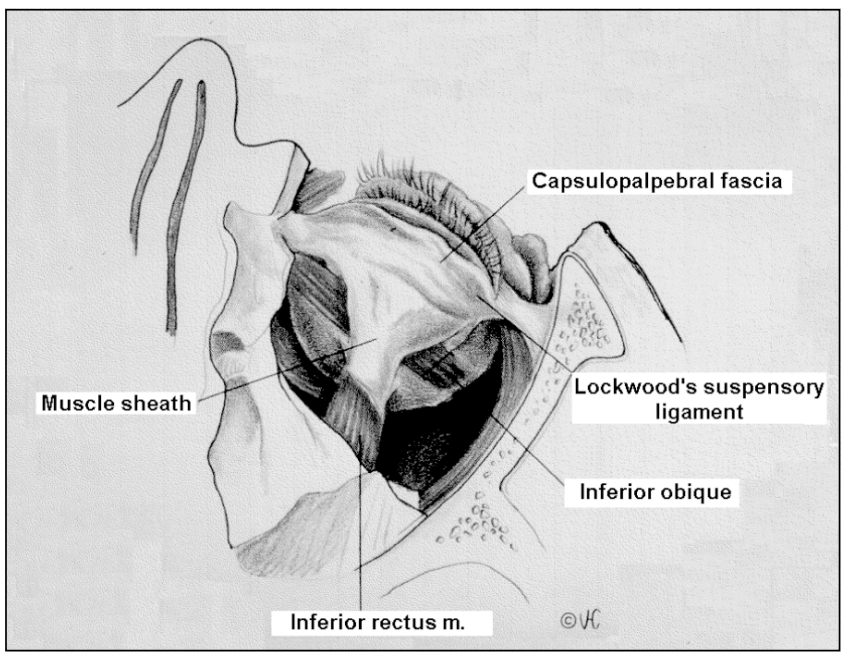

Figure 6) View from underneath the eyeball to show the capsulopalpebral and Lockwood's suspensory ligaments attached to both retinacula. Lockwood's suspensory ligament supports the eyeball in position within the orbit. Reprinted with permission from: Smith BC, Della RC, Nesi FA, et al. Ophthalmic Plastic and Reconstructive Surgery, vol 1. St Louis: Mosby Co, 1987

the inferior orbital rim. With this method the herniated fat pads are reduced instead of excised, and the lower, or ocular, capsulopalpebral flap is sutured to the arcus marginalis (Figure 7). This not only keeps the reduced fat pads in place but also raises and projects the eyeball forward, thereby treating and preventing enophthalmia (Figures 8,9). This procedure never interferes with eyelid or eyeball movement. A gap is created below the upper, or ciliary, flap, but this gap is no larger than that produced in conventional transconjunctival blepharoplasty and it re-epithelializes within a few hours. The cutaneous approach using the capsulopalpebral fascia was first described by De la Plaza and Arroyo (9). They sutured the capsulopalpebral fascia to the arcus marginalis to manage herniated fat pads and improve enophthalmia. This technique was popularized by Mendelson (10). The authors of this paper find it much simpler to use the conjunctival approach, a bloodless technique that avoids being surgically aggressive at the junction of the preseptal orbicularis muscle and the orbital septum. Such aggression may cause a linear and downward pull on the lid and is the most common cause of scleral show. Of course, excessive skin resection and excision or paresis of the pretarsal orbicularis muscle are other common causes of scleral show.

\section{SCLERAL SHOW}

The best method of managing scleral show (Table 5) is a lateral canthopexy (Figure 3), preferably with an incision of the capsulopalpebral fascia, done through the transconjunctival approach as in the management of herniated fat pads. In severe cases, one could graft some mucosa from the hard palate and suture it with plain or chromic catgut in the conjuctival defect (11-14). This graft acts as a 'spacer' and its height should be twice that of the preoperative amount of retraction to compensate for resorption and shrinkage. Hard palate mu- 


\section{TABLE 5: Management of scleral show}

1. Lateral canthopexy

2. Transconjunctival incision of the capsulopalpebral fascia with or without using the hard palate mucosa as a 'spacer'

3. Proper superficial musculo-aponeurotic system face lift (to reduce the downward pull of the cheek)

Avoid:

- Tarsorrhapy

- Skin graft

- Wedge resection

\section{TABLE 6: Improving the infraorbital sulcus}

1. Relocate premalar fat pad with the superficial musculoaponeurotic system

2. Reduce herniated palpebral fat pad by:

a) Canthopexy

b) Capsulopalpebral fascia

- Cutaneous approach (19)

- Transconjunctival approach (8)

3. Other techniques:

a) Fill in defect with herniated fat pad (16)

b) Tear trough implant (18)

\section{TABLE 7: Improving crow's feet}

1. Static

a) Brow ptosis: Treatment: Brow lift

b) Actinic or Senile: Treatment: Retin A, peelings, dermabrasion, laser resurfacing

\section{Dynamic}

a) Incise, excise or cauterize the vertical fibres of the orbicularis oculi muscle

Approaches:

- Canthopexy

- Brow lift

- Blepharoplasty (upper or lower)

- Face lift

b) Cover with the superficial musculo-aponeurotic system (20)

cosa is selected because it is composed of keratinized, stratified, squamous epithelium, unlike the rest of the oral mucosa (15). The authors do not recommend the use of tarsorrhaphy, skin grafting and wedge resection because these procedures rarely improve, and may worsen, the condition.

\section{INFRAORBITAL SULCUS}

A final observation of the ageing eye is the appearance of the infraorbital sulcus. With age, the soft tissues of the cheeks, including the premalar fat pads, gravitate downward, result-
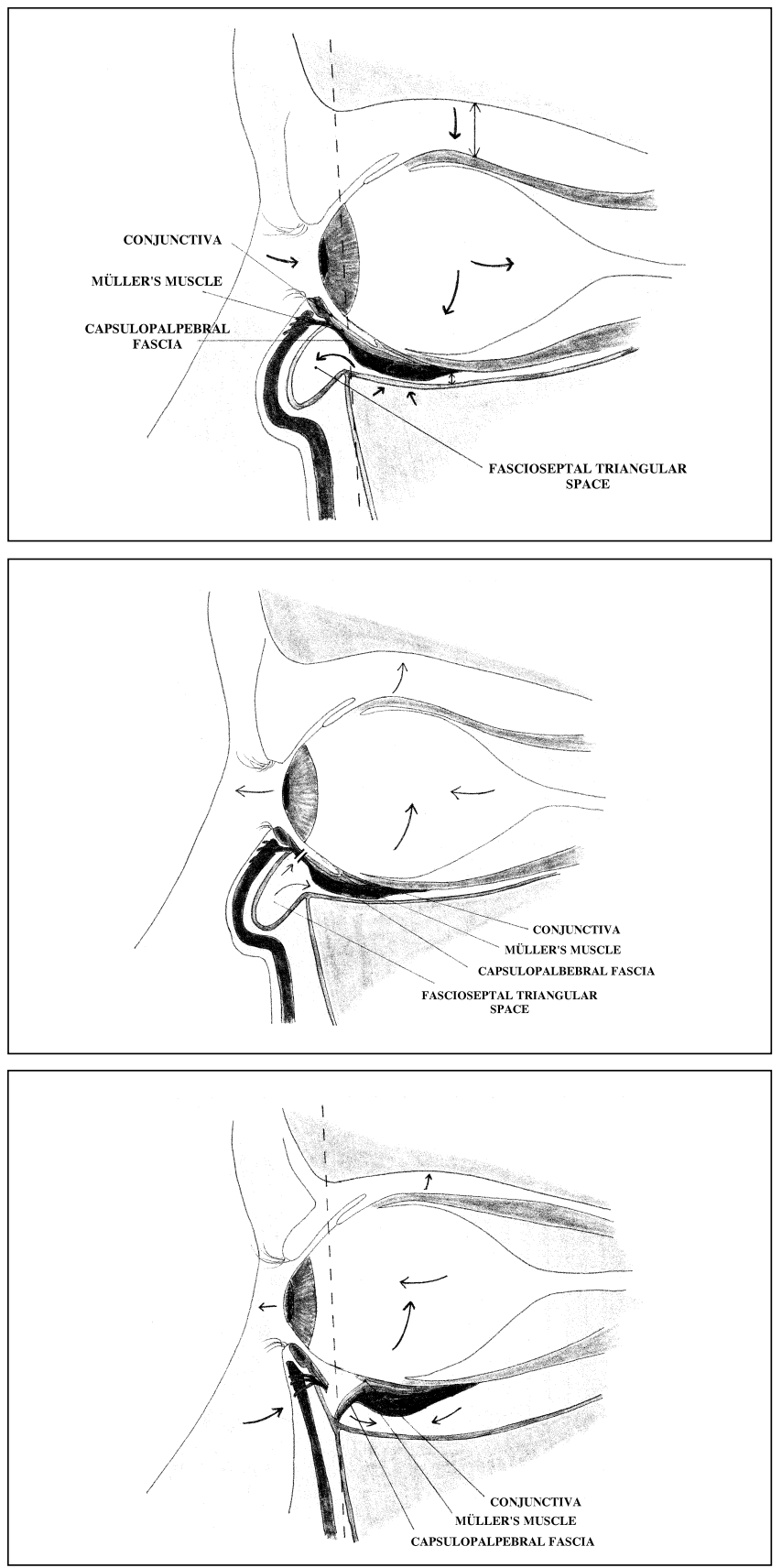

Figure 7) With age, because of lowering of Lockwood's suspensory ligament, the eyeball moves down and back and the orbital fat projects forward pushing the orbital septum, orbicularis oculi muscle and skin anteriorly (top). The capsulopalpebral fascia and inferior retractors muscle are incised through the conjunctiva and the herniated fat pad is reduced (centre). The fat pad is then contained by suturing the lower (ocular) flap of the capsulopalpebral fascia to the orbital rim and raising and moving the eyeball forward (bottom)

ing in infraorbital sulci, nasolabial folds and jowls. The sulcus is opposite the inferior orbital rim and is deepened by the herniated fat pads of the lower eyelids. Loeb (16) grafted or filled in the nasojugal furrow with the herniated fat pads; Hamra (17) mobilized the herniated fat pads to fill in this defect; and Flowers (18) created and successfully used the tear trough implant to fill in the deformity. The authors of this 

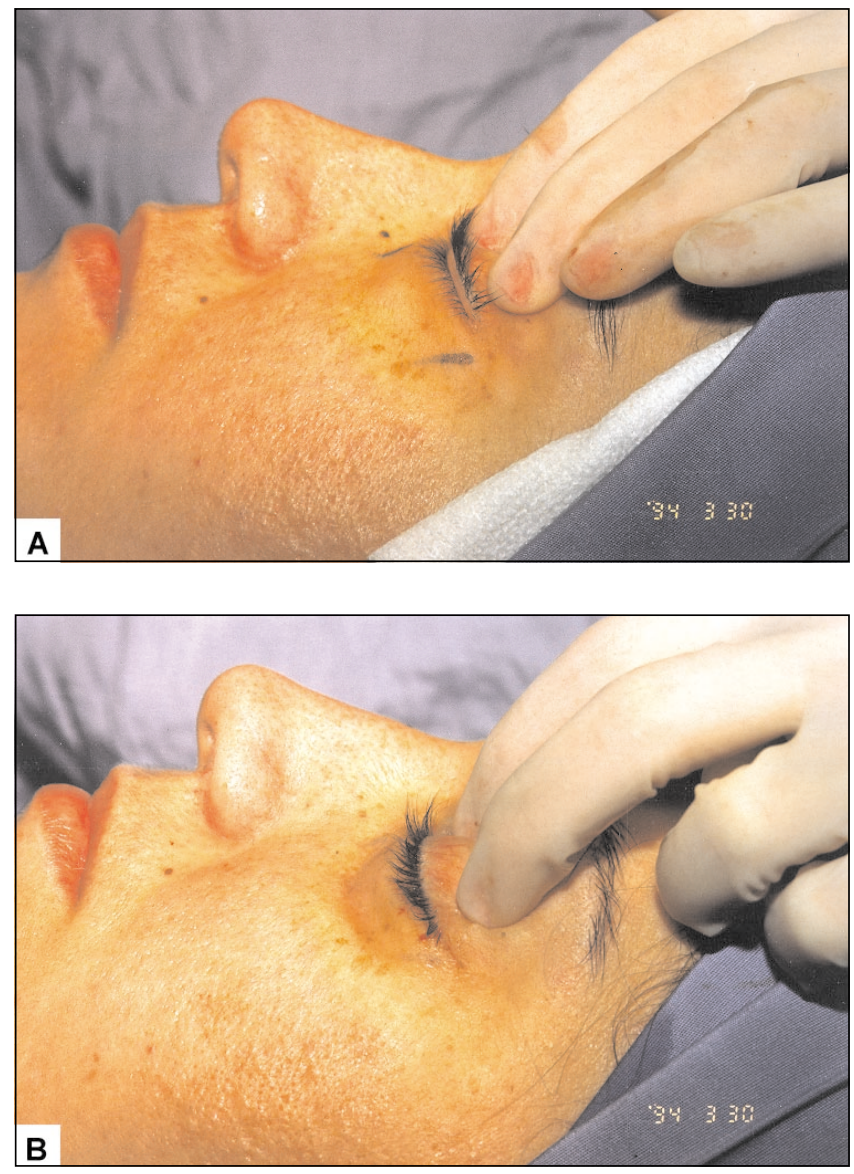

Figure 8) Preoperative decubitus position (A). Pressing the eyeball creates an enophthalmia and a herniated fat pad. Removing the herniated fat pad will only serve to maintain the enophthalmia. Postoperative decuvitus position (B). After reducing the herniated fat pad and maintaining the reduction with the capsulopalpebral fascia, pressure on the eyeball to the point of blanching the skin created neither a herniated fat pad nor an enophthalmia
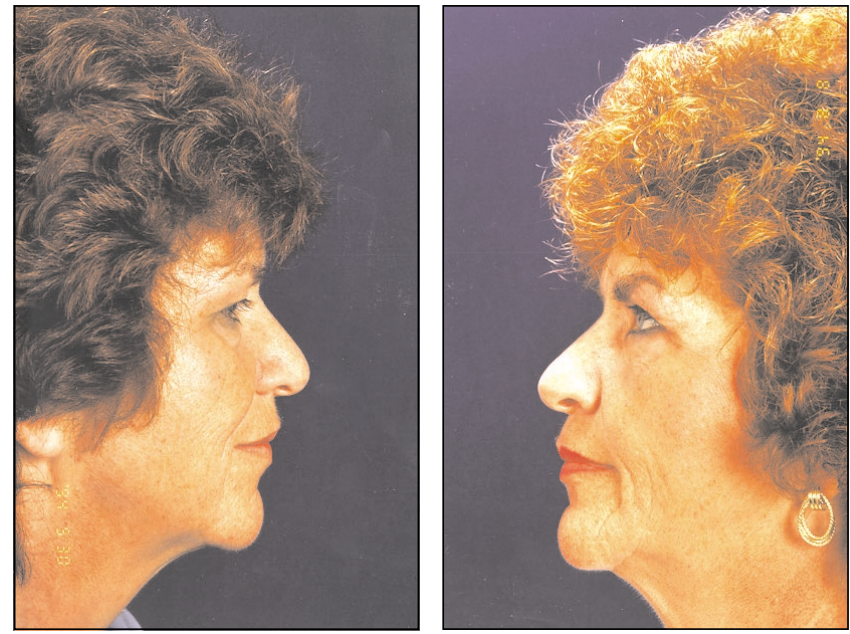

Figure 9) A patient with herniated fat pads (left) managed by reducing the herniated fat pads and maintaining the reduction with a transconjunctival approach using the capsulopalpebral fascia (right) study prefer to manage this condition by relocating the premalar fat pads with the superficial musculo-aponeurotic system (SMAS) during a face lift (19). Not only does this improve the infraorbital sulci (Table 6), but it greatly improves the herniated fat pads, cheekbones, nasolabial folds and jowls. This is one reason why the authors rarely, if ever, see an indication for liposuction of the nasolabial folds or jowls and even less for the premalar fat pads. Relocating this displaced fat is more physiological (attacks the pathophysiology of ageing), restores the anatomy of youth and gives a better and more natural-looking result.

In some cases, if further improvement is necessary, a face lift may be combined with either a reduction (relocation not excision) of the herniated fat pads by using the capsulopalpebral fascia through a transconjunctival approach or lateral canthopexy. If a patient refuses a face lift, the latter two techniques are less invasive and can be used to improve the defect.

Fogli (20) described a technique for improving the sulcus by buttressing the herniated fat pads with the SMAS. He used this method to cover the vertical fibres of the orbital orbicularis muscle, thereby improving dynamic crow's feet (Table 7). The authors have used this technique for several years.

\section{CONCLUSION}

With these techniques, skin is less often removed from the upper or lower eyelids and fat pads are seldom removed. The result is a natural appearance because the pathophysiology of the ageing eye is specifically attacked. Risks of complications arising from conventional upper and lower blepharoplasty, enophthalmia and retrobulbar hematoma are reduced.

\section{REFERENCES}

1. Camirand A. A comparison between parallel hairline incisions and perpendicular incisions when performing a face lift. Plast Reconstr Surg 1997;99:10-5.

2. Camirand A. Improvement to the scars of temporal and frontal face lifts. In: McKinney P, ed. Yearbook of Plastic Surgery. St Louis: Mosby, 1993:223-4.

3. Camirand A. Amélioration des cicatrices de lifting temporal et frontal. Ann Chir Plast Esthé 1991;36:215-7.

4. Camirand A. Amélioration des cicatrices de lifting temporal et frontal. The Premier Congrès Franco-Américain de Chirurgie Esthétique, Paris, June 1989

5. Camirand A. How to improve face lift scars. The Xth Congress of the International Society of Aesthetic Plastic Surgeons, Zurich, Switzerland, 1989;35.

6. Camirand A. Canthopexy and transconjunctival blepharoplasty are preferable to lower blepharoplasty. Can J Plast Surg 1994;1:184-7.

7. Camirand A, Doucet J. Surgical advances: a comprehensive approach to surgical rejuvenation of the eyes. Aesth Plast Surg 1996;20:15-22.

8. Camirand A, Doucet J. Reinforcing the orbital septum of the eye through a transconjunctival approach. Oper Tech Plast Reconstr Surg 1994;1:160-71.

9. De la Plaza R, Arroyo JM. A new technique for the treatment of palpebral bags. Plast Reconstr Surg 1988;81:677.

10. Mendelson BC. Herniated fat and the orbital septum of the lower lid. Clin Plast Surg 1993;20:323-30.

11. Henderson JW. Relief of eyelid retraction. Arch Ophthalmol 1965;74:205-16.

12. Harvey JT, Anderson RL. The aponeurotic approach to eyelid retraction. Ophthalmology 1981;88:513-24. 
13. Siegel R. Palatal grafts for eyelid reconstruction. Plast Reconstr Surg 1985;76:411-4.

14. Bartley GB, Kay PP. Posterior lamellar eyelid reconstruction with a hard palate mucosal graft. Am J Opthalmol 1989;107:609-12.

15. Kersten RC, Kulwin DR, Levartovsky S, Tiradellis H, Tse DT. Management of lower-lid retraction with hard palate mucosa grafting. Arch Ophthalmol 1990;108:1339-43.

16. Loeb R. Naso-jugal groove leveling with fat tissue. Clin Plast Surg 1993;20:393-400.

17. Hamra ST. The role of orbital fat preservation in facial aesthetic surgery: a new concept. Clin Plast Surg 1996;23:17-28.

18. Flowers R. Tear trough implants for correction of tear trough deformity. Clin Plast Surg 1993;20:403-15.
19. Camirand A, Doucet J, Harris J. Managing the infraorbital sulcus of aging. Can J Plast Surg 1996;4:221-3.

20. Fogli A. Orbicularis muscleplasty and face lift: a better orbital contour. Plast Reconstr Surg 1995;96:1560-70.

\section{FURTHER READING}

Camirand A, Doucet J, Harris J. Anatomy, pathophysiology and prevention of senile enophthalmia and associated herniated lower eyelid fat pads. Plast Reconstr Surg. (In press)

Camirand A, Doucet J, Harris J. The aging eye: Pathophysiology and management. In: Braverman MH, Tawes RL, eds. Surgical International Technology International V. San Francisco: Universal Medical Press Inc, 1996:347-51.

Camirand A. Management of the lower eyelid. Panel discussion. Aesthetic Plast Surg 1997;21:45-52. 